\title{
The Criminal Law Regulation of the Behavior of Fabricating and Deliberately Disseminating False Information of Epidemic
}

\author{
Tingting Zhang \\ Lecturer, Guangdong University of Petrochemical Technology (Maoming, China); \\ Ph.D. Candidate, Macao University of Science and Technology (Macao, China) \\ E-mail:939372833@qq.com \\ https://orcid.org/0000-0002-1950-5709
}

Zhang, Tingting (2020) The Criminal Law Regulation of The Behavior of Fabricating and Deliberately Disseminating False Information of Epidemic. Ukrainian Policymaker, Volume 6, 104-113. https://doi.org/10.29202/up/6/10

As of January 2020, the outbreak of the COVID-19 epidemic began that affected China and the whole world. Contrary to the efforts of people from all walks of life to contain the epidemic, illegal activities, even crimes, that interfere with the prevention and containment of the virus frequently occur, among which, making and maliciously spreading misinformation related to the epidemic is very common, which action, obstructs the efforts of virus prevention and containment as well as results in a substantial harm to the social stability and public order. The state authorities concerned, encountered by such challenge, have made efforts to crack down upon this kind of act. However, as in criminalization of such acts, it remains disputed in theory and difficult in identification in practice, determination of such a crime of making and maliciously spreading epidemic-related misinformation remains unsatisfactory in effect. This thesis conducts an analysis and puts forward proposals on the questions that arise in the criminalization of such act by the Criminal Law, which may be broken into three parts: firstly, it analyzes the justifiableness of criminalization of making and maliciously spreading epidemic-related misinformation from the perspective of jurisprudence; secondly, it offers after analysis and comparison principles that should be followed in the criminalization of such act; and thirdly, it reviews the issues of categorization, legal basis thereof and crime determination and exculpations under Article 291.1.1, Article 291.1.2 and Article 293 of the Criminal Law, and offers proposals on criminal law application.

Keywords: COVID-19, epidemic misinformation, criminal law, deliberately disseminating false information, fabricating false information

Received: February 25, 2020; accepted: March 20, 2020

(C) Zhang, Tingting, 2020 


\section{Introduction}

As from the beginning of this year until now, the information related to the COVID-19 epidemic has become the center of attention of the society (Ma, 2020; Saxena, 2020). This epidemic not only threatens the lives and health of people, but also seriously jeopardizes the normal order of the whole nation and the society. In sore need of epidemic prevention and control, a majority of provinces nationwide have exercised a stringent public control, which makes cell phones and the Internet the important methods for communication with the outside world. People become aware of updates on the epidemic prevention and control and express their personal opinions through Internet media. In connection with such information communication, there appear numerous cases of spreading of misinformation related to the epidemic on the Internet. By entering the keyword of "epidemic-related misinformation" on Baidu and Google and other search engines, more than tens of thousands of results came up. Certain kinds of acts of making or maliciously spreading epidemic-related misinformation, given their serious damage to the society, has an attribute of substantial social harm and hence is a violation of criminal law. Regulation of such crimes is not only prevention and a battle against epidemic but also a testing ground for the governance capability and the rule of law degree of the nation (Tan, 2020). The competent national authorities have mounted severe attacks on the act of making or maliciously spreading of epidemic-related misinformation in an attempt to maintain the stability of the nation and the public order (Bazaluk \& Balinchenko, 2020; Svyrydenko \& Stovpets, 2020). Then, resolution of such questions becomes urgent, among other things, why the criminalization is justifiable, how disputes on the determination of such crime are solved.

\section{Justifiableness Analysis of Criminalization of Making or Maliciously Spreading Epidemic-related Misinformation}

\section{The act has social harms}

The element of social harm, as a "central nervous system" of the criminal law, is the defining attribute of a crime. No activities are deemed a crime if without any social harm. However, will any act that has a social harm be a crime necessarily? The answer is no. The proviso provision of Article 13 of the Criminal Law provides that, any offense, though having a social harm, it is apparently not serious, will not be deemed a crime, which clause is an exculpation clause in the Criminal Law on those offenses that have the element of "social harm" but is apparently not serious. The questions then arise as to how the social harm shall be evaluated, and how the severity of social harms shall be determined. These questions, in essence, are strongly subjective, and people applying laws may find it very difficult to evaluate whether an act amounts to a crime in judicial practice due to a lack of a clearly delineated standard of determination.

Determination of the element of "social harm" in the act of making or maliciously spreading epidemic-related misinformation committed during the epidemic prevention and control shall be made in a historical and holistic manner, and in the way of "perceiving essence by looking through the appearances." Firstly, the element of social harm is constantly evolving, and the standard of evaluating social injury may vary, depending on the time period, social conditions. During an epidemic, the society is volatile, and the public is more sensitive, people are nervously tense, and making or maliciously spreading misinformation contrary to 
the public order and epidemic prevention and control during such time period will have more recipients, more serious impact and social harm as opposed to in normal times. Secondly, the determination of social harms is multi-factored. Hence evaluation of such an act shall be conducted in a holistic manner by considering both subjective and objective elements of the actor in a comprehensive way. Acts are the results of the actor's motives, and evaluation shall not only include evaluation of under what kind of subjective mind the actor is conducted but also consideration of the tangible and intangible harms resulted from such resulting harm, especially the intangible harm to the social order and people's psychological well-being resulting from such epidemic-related information. Thirdly, on its face, making or maliciously spreading epidemic misinformation is only a dissemination of misinformation. Still, in essence, the motive behind this act is not only to catch people's eye, but may also be intended to disrupt the public order and cause social panic, benefitting themselves. In summary, it's safe to conclude that the act of making or maliciously spreading epidemic-related misinformation has social harms and hence possesses the essential attribute of a crime.

\section{The Act of Making or Maliciously Spreading Epidemic-related Misinformation is a Criminal Offense}

"Criminal offense" is a legal attribute of a crime, and only those acts that violate a criminal law may be deemed a crime. Possession of a nature of criminal offense literally means that the actor's act violates the provision of the Criminal Law and, therefore, shall be subject to a negative treatment by the Criminal Law. "No conviction without law, no punishment without law," a Greek expression of law, discloses the underlying attribute of the principle of "legality" on conviction and punishment. Possession of a social harm does not in and of itself determines whether such act is a crime or not, and only when such act also breaks a criminal law, shall such act become one punishable by the Criminal Law, and only when may we determine that such act is a crime. Therefore, the "legality" principle is relatively more objective and reasonable in the determination of a crime.

The crime of making or maliciously spreading epidemic-related misinformation are mainly linked to the crime of "making, maliciously spreading terrorist misinformation" under Article 291.1.1, the crime of "making, maliciously spreading misinformation" under Article 291.1.2, and the crime of "defiance and affray" under Article 293 of the Criminal Law. How to specifically apply the name will be elaborated in the latter part of this article. If the act of making or maliciously spreading epidemic-related misinformation meets the constitutive elements of any of those crimes referenced above, then it is an act prohibited by the Criminal Law, and is a criminal offense. Currently, a majority of cases that arose relating to the making and maliciously spreading epidemic misinformation possess the constitutive elements of a certain crime mentioned above and is a criminal offense.

The Act of Making or Maliciously Spreading Epidemic-related Misinformation Possesses the Attribute of Culpability

Culpability is an essential attribute of a crime, which is more properly termed as "criminal culpability." As a consequence of the law, criminal liability is different from other results at law. It is widely known that any crime that has serious social harms violates the provisions of the Criminal Law and harms certain legal interests protected by the Criminal Law. Hence it shall be subject to the most severe kind of punishment, i.e., criminal penalties. Proper perception of criminal culpability shall be made by first perceiving the difference between the proviso 
of Article 13 of the Criminal Law and Article 37 of the Criminal Law, which is, in general terms, that acts that are not criminally penalized shall be divided into acts "not ought to be penalized" and those "not needed to be penalized." For instance, in evaluating whether any act of making or maliciously spreading epidemic-related misinformation possesses the element of "criminal culpability", if the act is "minor in offense degree and of minor harm, the actor may be exempted from criminal penalty." That act shall fall under the category of acts "culpable but not required to be penalized," and hence one may not deem such action as not a crime. Article 13 of the Criminal Law is positively exculpatory in effect, however, in evaluating an act of making or maliciously spreading epidemic-related misinformation, one is required to conduct an objective review of both the subjective and objective factors on the act, and may not exculpate such act arbitrarily by reliance on the proviso of Article 13 .

In conclusion, the act of making or maliciously spreading epidemic-related misinformation possesses the three attributes of a crime. Hence the criminalization of such act is justifiable.

\section{Principles on Criminalization of Making or Maliciously Spreading Epidemic-related Misinformation}

Speech freedom is a right granted by the Constitution to each citizen. At the same time of protecting such right, laws also regulate and places constraints on the speech-related crimes. During the epidemic, people are more tended to pay attention to epidemic-related information. Fake epidemic-related information not only misleads people and hence adversely affects their lives, it more importantly, seriously disrupts the public order and obstructs the epidemic prevention and control by the nation. Therefore, it is proper that the Criminal Law criminalizes the act of making or maliciously spreading epidemic-related misinformation, however, cautiously and reasonably, but this criminalization shall not go excessively or too broadly in the application of the Criminal Law. This author is the opinion that, in doing so, the three principles on criminalization shall be observed, namely, principles of modesty, "consistency between subjective and objective facts," and "consistency between crime and penalty."

\section{The principle of modesty of criminal law application shall be adhered to}

The criminal penalty is a necessary evil without other choices. Proper criminal law application will create benefits for the society and individuals; verse visa. We shall be alert to especially the expansion and abuse of criminal law application, and shall be cautious that only when there is no other alternative may we apply the "necessary evil" (Chen, 2013: 189). The criminal law, as a safeguard of other laws, possesses the attributes of the broadness of coverage and severity in punishment, etc. The criminal law shall possess a character of "modesty" and shall not be applied unless it is necessary, and arbitrary expansion of the coverage of its application shall not be tolerated in any event. "Criminal law is like a double-edged sword, when applied improperly, will inflict damage to both the nation and individuals." There shall be no exception in the criminalization of the act of making or maliciously spreading epidemicrelated misinformation. Not all untrue epidemic-related information disseminated during an epidemic has serious social harms or shall be subject to the regulation of criminal law. To those acts that are minor in degree of defense and of minor harms and hence solvable by use of other kinds of law, criminal law shall not arbitrarily be applied. Otherwise, it not only will not be reductive to the maintenance of public order and social stability but also will intensify the panic of people and result in chaos in the society during the epidemic. 
The Principle of "Consistency between Subjective and Objective Facts" shall be Adhered to

In determining the existence of a crime of making or maliciously spreading epidemicrelated misinformation, one shall adhere to the principle of "consistency between subjective and objective facts." If the objective element of the crime is present for an act, one shall also stress the finding of an "intention to act" for the subjective element. For the result of a subjective intent, the awareness and will of the actor shall be primarily considered. Namely, the evaluation shall be conducted on whether the act of making or maliciously spreading misinformation conducted by the actor is controlled by the self-awareness and will of the actor. Further, one shall also conduct a holistic analysis, namely, subjective and objective analysis of the actor's cognizance, education, purpose, environment etc. Take a rural woman that does not possess the ability to tell true epidemic information from a fake one as an example, if she merely intentionally spreads the epidemic information without checking it, which is later confirmed as untrue, that women shall not be deemed to have committed such a crime. The subjective intent evaluation here mainly includes a finding of whether the actor is "aware of" of the false information and its harms that result from his/her dissemination, as well as of whether the actor is positive or negative on the harmful effect. In sum, in criminalizing the act of making or maliciously spreading epidemic-related misinformation, the principle of "consistency between subjective and objective facts" shall be adhered to, and "conviction merely in reliance of objective facts" shall be prohibited.

\section{The Principle of "Consistency between Crime, Liability and Punishment" shall be Adhered to}

Capitalist enlightenment thinkers and jurists in the $17^{\text {th }}$ and $18^{\text {th }}$ centuries are the first to proffer the principle of consistency between crime, liability, and punishment. According to Montesquieu, "criminal penalties shall be in different degrees, and severity of penalties shall be determined according to the seriousness of offenses" (Montesquieu, 1958:140). Beccaria pointed out in his treatise, On Crimes and Punishments, that "the more harm a crime does to the public interest, the stronger the power that prompts people to commit crimes, the means to deter crimes shall be more powerful. Therefore penalties shall be in alignment with crimes (Beccaria, 1993: 63). Finding a perfect balance point between crimes and punishments has been a lofty goal for people engaged in criminal law application having such a faith. This principle, when applied in practice, maybe summarized into one sentence, namely, "appropriate punishments according to the degree of crimes." During the epidemic, the State has made numerous efforts for the maintenance of the public order. However, in the evaluation of any act of making or maliciously spreading epidemic-related misinformation, the principle of consistency between crime, liability and punishment shall be observed. One shall not assign a more serious crime to such activities in the conviction or impose a more serious punishment or impose a punishment at a more serious level by yielding to certain needs in a special time. Conviction and sentencing of the act of making or maliciously spreading epidemic-related misinformation shall be based on an evaluation by considering all objective and subjective facts. Indeed, there may be an exception where the act in itself has exceeded the normal limits in conviction and sentencing. Therefore the act shall be subject to a more severe crime and punishments, however in principle and in general the regulation of such act shall be in compliance with the principle of consistency between crime, liability and punishment. 


\section{Application of Criminal Law for the Act of Fabricating and Intentionally Disseminating False}

\section{Information about an Epidemic}

According to the above legal thinking, the act of fabricating and intentionally disseminating false information about an epidemic must be the object of the perspective of criminal law, and shall follow certain principles in the process of being governed by criminal law. On February 6, 2020, the Supreme People's Court, the Supreme People's Procuratorate, the Ministry of Public Security and the Ministry of Justice jointly issued the Opinions on Punishment of Crimes against the Prevention and Control of Pneumonia Infected by COVID-19 according to Law (hereinafter referred to as the "Opinions on Punishment of Pneumonia Prevention and Control Crimes"), clearly stipulating that "Whoever fabricates false information on the epidemic, disseminates the same on information networks or other media, or knowingly disseminates false information on information networks or other media and thus seriously disturbs social order, shall be convicted of the crime of fabricating or intentionally disseminating false information." However, in judicial practice, the relevant provisions of the Criminal Law and the judicial interpretations related to it should not be completely abandoned because of the introduction of this provision of the Opinions. In the author's opinion, in addition to the crime of fabricating and intentionally disseminating false information about an epidemic as set forth in Article 291.1.2, the crime of fabricating and intentionally disseminating false terrorist information as set forth in Article 291.1.1, and the crime of picking quarrels and provoking troubles in Article 293 should also be the objects of the research on criminal laws and regulations.

\section{Choice of Crimes and Legal Basis}

1. Crime of fabricating and intentionally disseminating false information. The added Article 291.1.2 of the 2015 Amendment (IX) of the Criminal Law stipulates the crime of fabricating and intentionally disseminating false information. Prior to this, the fabrication and dissemination of false information related to an epidemic was not regulated by a provision in the Criminal Law. At the beginning of this year, during the epidemic prevention and control, the Supreme People's Court, the Supreme People's Procuratorate, the Ministry of Public Security and the Ministry of Justice jointly issued the Opinions on Punishment of Pneumonia Prevention and Control Crimes, giving a clear guidance to the regulation of general fabrication and intentional dissemination of false information about the epidemic. But we should distinguish from the guidance behind its original intention of promulgation, among the three crimes, the statutory punishment of the crime of fabricating and intentionally disseminating false information is the mildest. In the critical period of the national fight against the epidemic, people are in a relatively closed social space, and the special period, special environment, and special psychology cause people to relatively easily use the network and media to disseminate false information of the epidemic situation. In such a case, even if some epidemic rumors have certain social harm, we should comprehensively consider the application of the less legal punishment for the crime of fabricating and intentionally disseminating false information; and the promulgation of such guidance by the competent authorities reflects the principle of modesty of criminal law.

2. Crime of fabricating and intentionally disseminating false terrorist information. Article 291.1.1 of the Criminal Law provides for the crime of fabricating and intentionally 
disseminating false terrorist information. This provision does not mention any information about an epidemic, but, according to Article 10 of the Interpretation of Certain Questions Concerning the Specific Application of Law in Criminal Cases Involving Obstruction of Prevention and Control of Emergent Infectious Diseases and Other Disasters (hereinafter referred to as the "2003 Interpretation") promulgated by the Supreme People's Court and the Supreme People's Procuratorate in $2003^{1}$ and Article 6 of the Interpretation of Certain Questions Concerning the Application of Law in the Trial of Criminal Cases Concerning the Fabrication and Intentional Dissemination of False Terrorist Information (hereinafter referred to as the "2013 Interpretation") promulgated by the Supreme People's Court in $2013^{2}$, it is also necessary to consider whether the crime can be applied when regulating the act of fabricating and intentionally disseminating false information about an epidemic. The crime of fabricating and intentionally disseminating false terrorist information in Article 291.1.1 is different from the crime of fabricating and intentionally disseminating false information in Article 291.1.2 only in the word "terrorist." According to the contents of the above two judicial interpretations, it is not difficult to see that the 2013 Interpretation clearly explains false information about such as major epidemic as false terrorist information, while the crime of fabricating and intentionally disseminating false information is only aimed at a general epidemic. From this difference, the application of the law for the two crimes can be judged by the severity of false information about the epidemic, for example, the act with a serious threat to public security and likely to cause social panic or public security crisis, or with severe social harm, is convinced of the crime of fabricating and intentionally disseminating false terrorist information according to Article 291.1.1 of the Criminal Law. At the same time comparing the legal punishment of the two crimes, the crime of fabricating and intentionally disseminating false terrorist information is slightly heavier than the crime of fabricating and intentionally disseminating false information in Article 291.1.2, which is also in line with the principle of the adaptation of crime, duty and punishment.

3. Crime of picking quarrels and provoking troubles. Article 293 of the Criminal Law provides for the crime of picking quarrels and provoking troubles. This article does not deal with the content of false information, let alone the provisions on false information about an epidemic. Why do we need to discuss this crime in the course of studying the application of criminal law to the act of fabricating and intentionally disseminating false information about the epidemic? The reason lies in Article 5 of the Interpretation of a Number of Issues Concerning the Application of Law on Handling Criminal Cases of Defaming, etc. with Network (hereinafter referred to as "the Interpretation of Network Defamation") promulgated by the Supreme People's Court and the Supreme People's Procuratorate in 2013 ${ }^{3}$. The

${ }^{1}$ Article 10 of the 2003 Interpretation stipulates that: "Whoever fabricates terrorist information related to disasters such as outbreak of infectious diseases, or knowingly disseminates such terrorist information in order to seriously disrupt public order shall be convicted and punished for the crime of fabricating or intentionally disseminating false terrorist information."

${ }^{2}$ Article 6 of the 2013 Interpretation stipulates that: "False terrorist information refers to the untrue information about the occurrence of explosion threat, biochemical threat, radiation threat, aircraft hijacking threat, major disaster, major epidemic and other serious public security incidents, which may cause social panic or public security crisis.

${ }^{3}$ Article 5 of the Interpretation of Network Defamation stipulates that "Whoever fabricates false information, or knowingly fabricates false information, disseminates or organizes personnel to disseminate the same via information network, or makes troubles, causing serious public disorder, shall be convicted and punished with the crime of picking quarrels and provoking troubles." 
fabrication and dissemination of false information about an epidemic should also be covered by the Interpretation of Network Defamation. The Interpretation of Network Defamation regard the act of fabricating false information and disseminate the same on the network as the crime of picking quarrels and provoking troubles, the "false information" in Article 291.1.2 of the Criminal Law refers to all false information about danger, epidemic, disaster and warning, etc., the two articles have a certain relationship of concurrence of articles of law. According to the principle of higher-level law preferred than lower-level law and the principle of a legally prescribed punishment for a specified crime, the author believes that the crime of fabricating and intentionally disseminating false information is applicable for the false information about an epidemic. Except that, the crime of picking quarrels and provoking troubles should be applied for any other false network information.

\section{Controversy over the Determination of Crime and Non-crime}

1. Understanding of "dissemination via network media." Article 291.1.2 of the Criminal Law, the objective aspect of the crime of fabricating and intentionally disseminating false information is "disseminating information via information networks or other media." The components of this crime require that the perpetrator intentionally disseminates false information on the information network platform or other media. For example, the perpetrator fabricates the false information on an epidemic and does not disseminate it via any network, but intentionally disseminates the same in the public gathering place in real life, causing public panic and severe social harm. So can the dissemination via non-network media be the basis of the crime? The author believes that the answer is no. The dissemination of the information network platform or other media is an objective aspect of the crime. Still, it cannot be considered that the network media in this crime is unique and exclusive because of fabricating and intentionally disseminating false information about the epidemic via network media. Imagine, if the dissemination of false information orally, with leaflets or in any other way, its social harm from that place is not less severe than that via network media. According to the principle of the adaptation of crime, duty, and punishment of the Criminal Law, whether to disseminate false information via network media cannot become the standard to determine such crime.

2. Understanding of "seriously disrupting public social order." When determining the act of fabricating or intentionally disseminating false information about an epidemic as the crime of picking quarrels and provoking troubles or the crime of fabricating or intentionally disseminating false information, we will have an issue, which is the understanding of "seriously disturbing public order." Although there are subtle and literal differences between the two crimes on the stipulation of "seriously disturbing the public order," they have the same regulating purpose in criminal law for the prevention and control of false information about an epidemic. Both belong to the crime of fabricating or intentionally disseminating false information or the crime of fabricating or intentionally disseminating false terrorist information as stipulated in Article 291 of the Criminal Law, and, should also have the same meaning in the perspective of systematic interpretation as "seriously disturbing public order". There are six criteria to determine "seriously disturbing the social order" for the crime of fabricating or intentionally disseminating false terrorist information in the 2013 Interpretation. In the author's opinion, for the determination of the crime of the picking quarrels and provoking troubles or the crime of fabricating or intentionally disseminating false information or the crime of fabricating or 
intentionally disseminating false terrorist information, the definition of "seriously disturbing public order" can be determined by reference to the six criteria of "seriously disturbing public order" as set forth in the 2013 Interpretation.

3. Understanding of "fabricating false information." During the epidemic period, it is an inevitable choice to regulate the act of fabricating and intentionally disseminating false information on an epidemic in order to maintain social stability. However, the excessive application of criminal law should be avoided in practice. If the information with only fiction is regarded as fabricated information, the information with exaggerated false elements is recognized as false information, the modesty of criminal law will be violated. In daily life, people expressing their emotional views, merchants in the process of selling goods, more or less, may have the elements of fiction and exaggeration, so such cases can be regarded as a crime determined according to the Criminal Law? The author thinks that, in determining whether the act of fabricating or intentionally disseminating false information about an epidemic is a crime, a criterion must be abided by: if the information exists objectively, not out of thin air, and the doer has processed the information in the process of dissemination, then the doer cannot be regarded as "fabricating information," nor can the information disseminated be regarded as "false information."

\section{Conclusions}

The epidemic from the beginning of 2020 has affected everyone's heart. China and all circles of society actively take action in the prevention and control of the epidemic in order to maintain the stability of public social order. For the law as an important tool to adjust the social relations, it is necessary to maintain the principle of law itself in the control of crimes related to the epidemic, rationally treat the act of fabricating and intentionally disseminating false information on the epidemic, and correctly apply the law for the regulation of such acts. This Paper demonstrates the rationality of the crime of fabricating and intentionally disseminating false information on the epidemic from the angle of legal theory. On the basis of this, the principles that should be followed in the process of regulating the acts are put forward to apply the criminal law properly in practice. In a special period, the law should take on a special mission, but it should not try to break through the limitation of the law because society is in a special period. The rational and objective view of the fabrication and dissemination of false information on the epidemic and the accurate application of the law is the proper and effective ways for law to maintain public social order and safeguard the fairness and justice of law during the epidemic period.

\section{므] References}

Bazaluk, Oleg, and Svitlana Balinchenko (2020) Dynamic Coordination of Internal Displacement: Return and Integration Cases in Ukraine and Georgia. Sustainability, 12, 4123. https://doi.org/10.3390/su12104123

Beccaria: On Crimes and Punishments, translated by Huang Feng, Encyclopedia of China Publishing House, 1993 Version.

Chen, Xingliang (2013) Guidance to Criminal Theories [M]. Beijing: Law Press Version. Ma, Bo (2020) Value Shaping of Ecological Man: External Standard and Internal Idea. Future Human Image, Volume 13, 2020: 57-65. https://doi.org/10.29202/fhi/13/6 
Montesquieu: Persian Letters (1985) Translated by Luo Dagang, People's Literature Publishing House.

Saxena, S. (eds) (2020) Coronavirus Disease 2019 (COVID-19). Medical Virology: From Pathogenesis to Disease Control. Springer, Singapore.

Svyrydenko, Denys, and Oleksandr Stovpets (2020) Cultural and Economic Strategies of Modern China: In Search of the Cooperation Models across the Global World. Future Human Image, Volume 13, 102-112. https://doi.org/10.29202/fhi/13/11

Tan, Yusheng (2020) Toward a law of healthy peoples: From the Perspective of the Right to Health. Future Human Image, Volume 13, 2020: 113-125. https://doi.org/10.29202/ fhi $/ 13 / 12$ 